\title{
A CASE OF TRUNCUS ARTERIOSUS
}

\author{
Sudeep Pathak, R. K. Singh.
}

1. Physician \& critical care specialist, Department of Cardiology, National Hospital \& Narmada Hospital Bhopal.

2. Cardiologist, Department of Cardiology, Chirayu Heart Hospital. Bhopal.

\section{CORRESPONDING AUTHOR:}

Dr Sudeep Pathak

3 Nupur Kunj E-3 Arera Colony.

Bhopal- 462016.

E-mail: pathakhospital@gmail.com

KEY WORDS: Truncus arteriosus, single arterial trunk, truncal anomaly, truncus.

INTRODUCTION: TRUNCUS ARTERIOSUS was first recognized in 1798 and account for $0.7-1.2 \%$ of all congenital Cardiac malformation. It occurs with equal frequency in males and Females. Truncus has been reported with Trisomy 18, Trisomy 21 and Chromosome 22q11 deletion. It is also been reported with Di George syndrome which include Hypertelorism, low set ears, Micrognathia, small fish like mouth, short down slanting palpebral fissure, absent pinna, cleft lip and high arch palate .

In TRUNCUS ARTERIOSUS, a single artery with a single semilunar valve leaves the base of heart and gives rise to pulmonary, Systemic and Coronary circulation. The single arterial trunk receives blood from both the ventricle so a ventricular septal defect is obligatory.

Anomalies associated with TA are Right aortic arch, Truncal valve abnormality coronary artery anomaly atresia of Right or left pulmonary artery, Atresia of ductus arteriosus, single ventricle, TAPVC, subclavian artery and SVC abnormality. At times Right aortic arch accompanies Truncus Arteriosus.

CASE REPORT PRESENTATION: Baby Boy, aged 4day Male was referred to Max critical care Neonatel institute, Fathegarh, Bhopal on 27 July 2012 with history of Respiratory distress ,Failure to thrive, Poor Feeding, Mild Cyanosis, Difficulty in breathing, Tachypnea for the past 1 day .

Examination

His Heart rate was $170 / \mathrm{min}$, Blood Pressure was $80 / 60 \mathrm{mmHg}$, Respiratory rate was $68 /$ minute, oxygen saturation was $67 \%$ sp02. ABG showed PAO2 of $60 \%$, PCO2 of $45 \%$. The baby was cyanosed, Jugular veins were distended, on palpation systolic thrill was palpable on mid left sternal border. On auscultation his second heart sound was loud and single, there was harsh systolic murmur (3/6), basal crepitations and cardiomegaly observed on examination.

INVISTIGATION : Hematology : Haemoglobin was 15.1gm\%, Total WBC count was 10,300/cu mm , Platelet count was 2,14000lac/cu mm, Blood sugar $69 \mathrm{mg} / \mathrm{dl}$, Serum protein was $6.30 \mathrm{mg} / \mathrm{dl}$ Albumin $3.7 \mathrm{mg} / \mathrm{dl}$, Sodium $137 \mathrm{meq}$, potassium was $4.8 \mathrm{meq}$, calcium was $9.6 \mathrm{mg} / \mathrm{dl}$, Bilirubin was total $10.90 \mathrm{mg} / \mathrm{dl}$, direct $1.30 \mathrm{mg} / \mathrm{dl}$, indirect $9.60 \mathrm{mg} / \mathrm{dl}$

His Chest X- Ray showed Cardiomegaly with prominent pulmonary markings, ECG showed peaked $\mathrm{P}$ wave in lead 2 and aVF and Biventricular( $\mathrm{LVH}+\mathrm{RVH})$ hypertrophy, axis was normal. 
His Echocardiography showed Type-1 Truncus Arteriosus; single arterial trunk giving rise to pulmonary trunk which in turn gave rise to right and left pulmonary artery. Single arterial trunk arises over both ventricles with large unrestrictive Ventricular septal defect with bidirectional shunt. He had Quadricuspid truncal valve with normal arch and normal SVC. Left coronary artery arising from left posterior aspect of truncus, right coronary arising from right anterior aspect of truncus

MANAGEMENT: He was put on assisted ventilation with fluids, diuretics, ACE inhibitor, and Antibiotics. He was advised surgery which parents were unable to get it done at such a short notice and baby died on 08 august 2012 due to cardiac failure.

DISCUSSION: Truncus Arteriosus is rare Congenital Cyanotic Heart disease which is characterized by single arterial trunk arising from heart which in turn gives rise to pulmonary trunk in various ways.

There are Four types of it is recognized, The most common variety is Type -1 which is characterized by short main pulmonary Artery that originate from truncus and give rise to Right and Left Pulmonary arteries. In Type - 2 Pulmonary artery arise from a separate ostia from the side of Truncus and in Type -3 Pulmonary arise from a separate ostia from back of Truncus .In Type -4 Pulmonary artery is absent or Atretic. Truncal valve could be Quadricuspid (40-50\%), bicuspid, Tricuspid or Hexa cuspid . Left Coronary artery arise from left posterior aspect of Truncus, right Coronary artery arise from right anterior aspect of Truncus. VSD is always Nonrestrictive, and roofed by Truncal valve setting a stage for Truncal valve regurgitation

They usually come to attention by first few week of life with Tachypnea, poor feeding, failure to thrive. These patients seldom reach their first birthday. On examination there will be evidence of Cardiomegaly , collapsing pulse, loud single second heart sound, systolic murmur( harsh , blowing , 3/6 - 4/6 , best heard 3/4 left intercostals space), preceded by ejection click .

Initially the pulmonary vascular resistance is low, as PVR rises after birth, the pulmonary vascular resistance becomes equal to systemic and causes Eisenmenger, cyanosis, and bidirectional shunting.

ECG showed Biventricular Hypertrophy. Chest X- Ray shows cardiomegaly with prominent Pulmonary vascular markings and unusually high hilar areas .Early surgical intervention is advised in all cases within first 2 month of life , in case of severe pulmonary Hypertension, surgery is contraindicated.

Operation consist of closure of VSD , leaving the aorta arising from left ventricle ; excision of pulmonary arteries from there truncus origin ; and a valve containing prosthetic conduit or aortic homograft valve conduit between the right ventricle and pulmonary arteries to establish circulatory continuity. Careful follow up for Pulmonary hypertension and Truncal conduit patency is done regularly. Endocarditis prophylaxis is required in all patients.

Patient in our study was admitted with history of Respiratory distress, Failure to thrive, Poor Feeding, Mild Cyanosis, and difficulty in breathing. His CXR showed Cardiomegaly with prominent pulmonary markings, ECG showed peaked P wave in lead 2 and aVF and Biventricular (LVH+RVH) hypertrophy, axis was normal.

His Echocardiography showed Type-1 Truncus Arteriosus; single arterial trunk giving rise to pulmonary trunk which in turn gave rise to right and left pulmonary artery. Single arterial trunk 
arises over both ventricles with large unrestrictive Ventricular septal defect with bidirectional shunt. He had Quadricuspid truncal valve with normal arch and normal SVC. Left coronary artery arising from left posterior aspect of truncus, right coronary arising from right anterior aspect of truncus.

He was put on assisted ventilation with fluids, diuretics, ACE inhibitor, and Antibiotics. He was advised surgery which could not be done and baby died due to cardiac failure.

CONCLUSION: Truncus Arteriosus typically comes to attention in early infancy because increase blood flow results in congestive cardiac failure. Cyanosis is mild or absent, Systolic murmur across VSD becomes evident as pulmonary vascular resistance falls. Main Pulmonary artery is palpable in Type one Truncus. There is decrescendo Systolic murmur maximum at left intercostals space with radiation upward to right. When pulmonary vascular resistance increases, the shunt across VSD is reduced and soft mid systolic murmur emerge across the truncal valve. Second heart sound is loud and single. ECG shows biatrial $\mathrm{P}$ wave and varying degree of ventricular hypertrophy.CXR shows increased pulmonary vascularity due to pulmonary arterial blood flow and increase pulmonary venous congestion. Pulmonary trunk is prominent in Type one Truncus. Left and right heart dilates in response to CCF and Truncal valve regurgitation.

Echocardiography reveals type of Truncus, relationship of Truncus to Right and left ventricle morphology \& functional derangement of Truncal valve and physiologic consequences of the malformation.

In management, surgery should be done at the earliest and should be followed up regularly for conduit patency and Pulmonary Hypertension.

\section{REFERENCES:}

1 Kodo K Nishizaway, Furutani . M Yamamure E, Joo K et al GATA6 Mutation causes human cardiac outflow tract defect by disrupting semaphoriin -plexin signaling. Proc Natl Acad Sci USA Aug 18 2009;106(33):13933-8

2 Lund AM, Vogel M, Marshal AC, Emani Sm, Pigula FA, Tworetzky W, et al. Early intervention on the pulmonary artery and Right ventricular outflow tract after neonatal or early infant repair Of Truncus Arteriosus using homograft conduits ,American journal of Cardiology Jul1 2011;108(1):106-13

3 Alexiou C, Keeton BR, Salmon AP, Monro. JL. Repair of Truncus Arteriosus in early infancy with antibiotic sterilized aortic homografts. Ann Thoracic surg. May 2001;71(5 supplement) :371-4

4 Swanson TM, Selamet Tierney ES, Tworetzky W, Pigula F, Mc Elhinney DB.Truncus Arteriosus: diagnostic accuracy, outcome and impact of prenatal diagnosis. Pediatr Cardiol. Apr 2009; 30(3):256-61

5 Russel HM, Pasquali SK, Jacobs ML, O’Brien SM, Mavroudis Cetal. Outcome of repair of common arterial trunk with truncal valve surgery: a review of the society of Thoracic surgeons congenital Heart surgery data base. Am Thorac Surg. Jan 2012; (1) :164-9.

6 Chen JM, Glickstein JS, Davies RR, et al. The effect of technique on post operative right side d obstruction in patient with Truncus Arteriosus.J Thorac Cardivascular Surg. March 2005;129(3):559-68 


\section{CASE REPORT}

Truncus Arteriouses: Single arterial Trunk with VSD in Long Axis

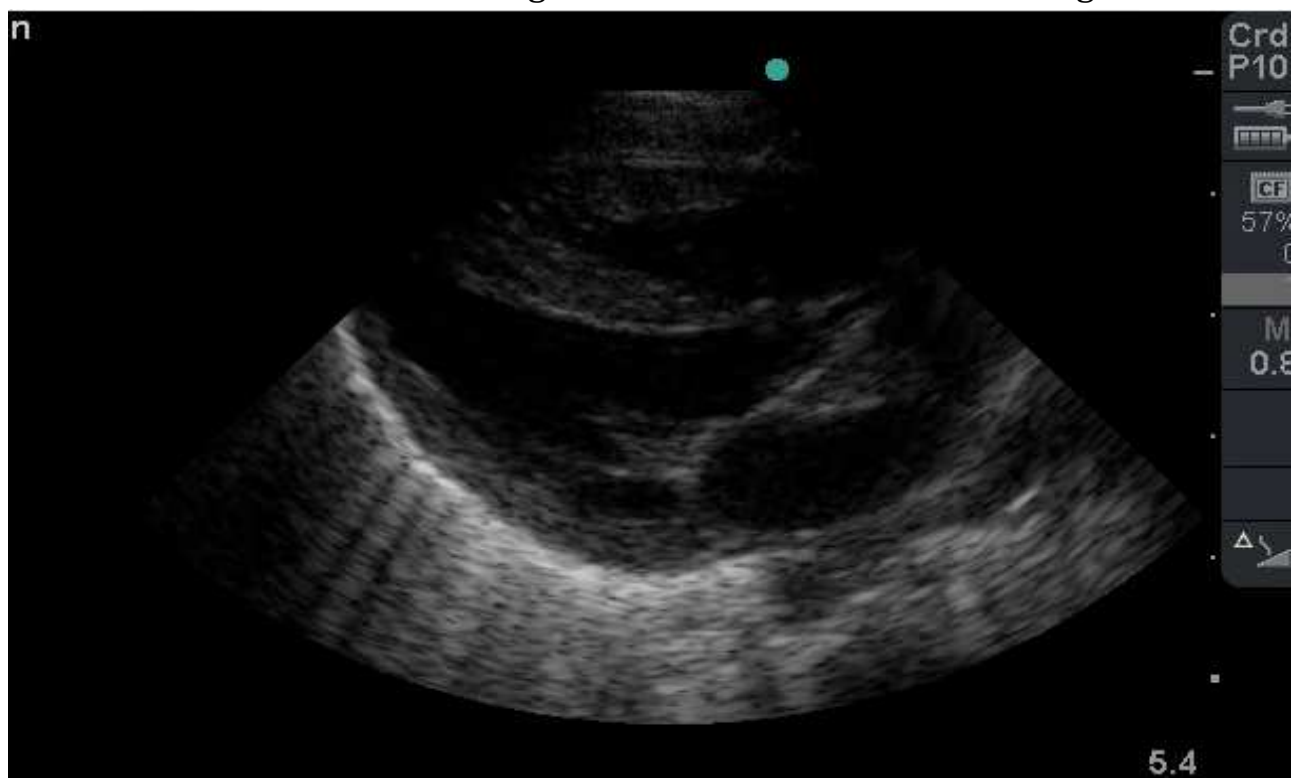

Truncus arteriouses: short axis view with single arterial trunk

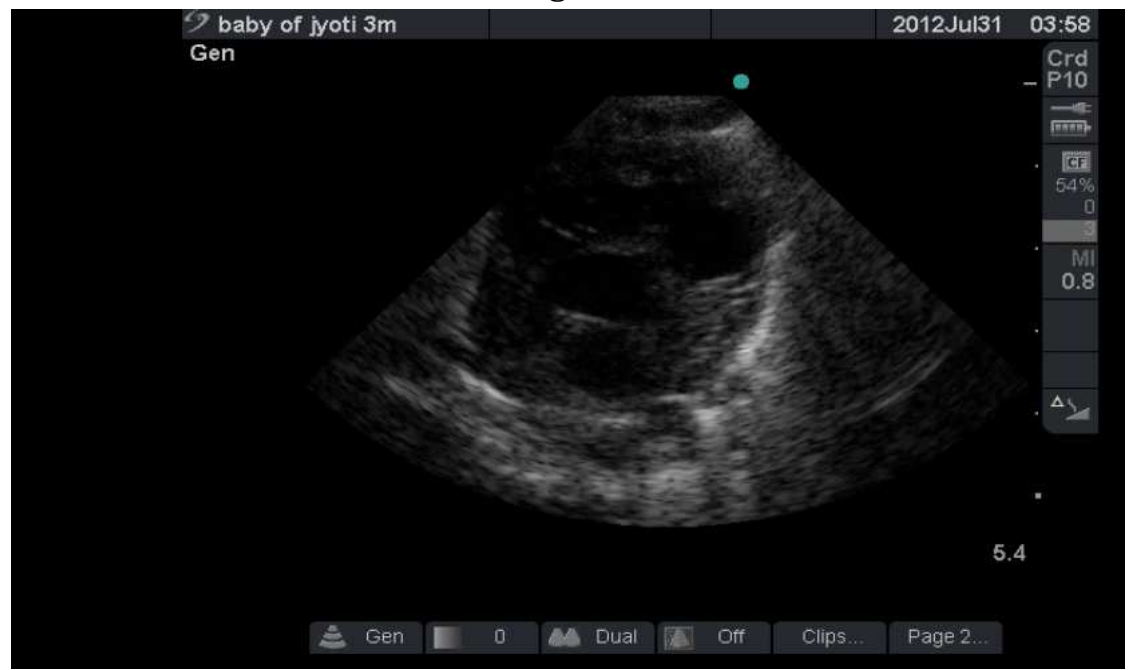




\section{CASE REPORT}

Truncus arteriouses: long axis with single trunk and vsd

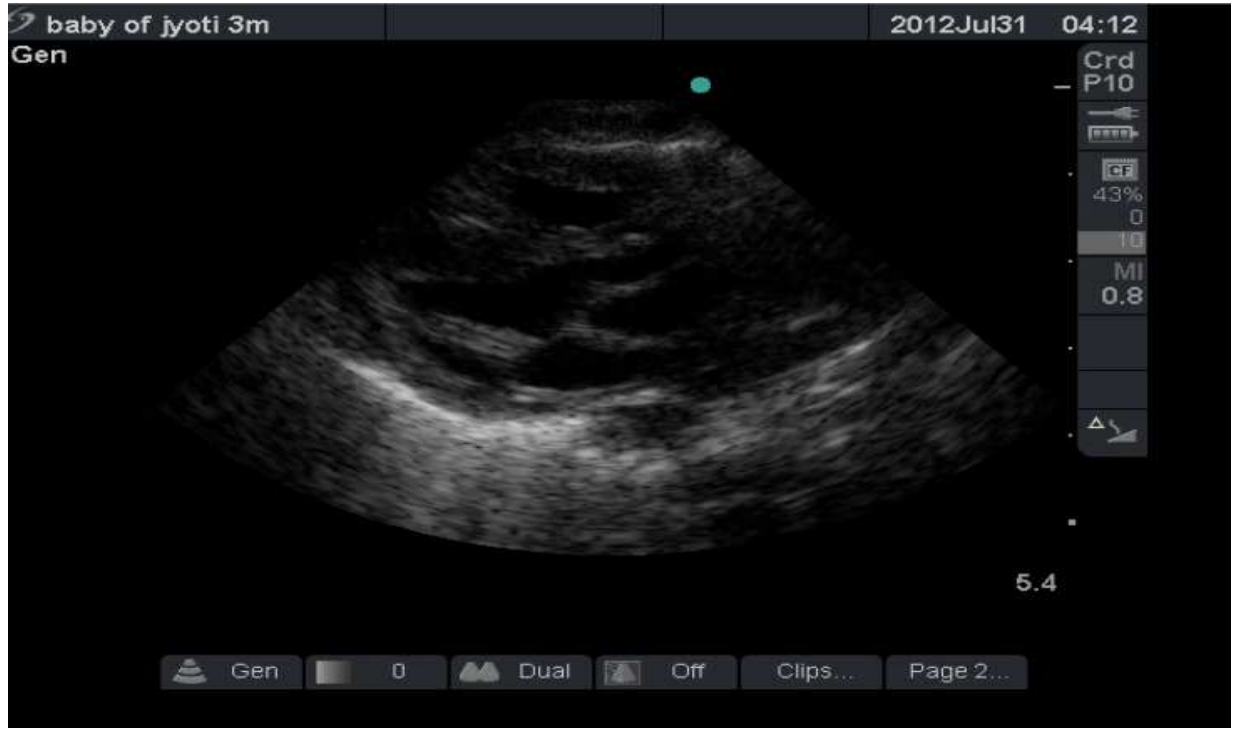

